\title{
Geochemistry of phosphorus in sediment cores from Sishili Bay, China
}

Article in Marine Pollution Bulletin · August 2016

DOI: $10.1016 /$ j.marpolbul.2016.08.050

CITATION

1

6 authors, including:

\section{Yong ZHANG}

Shandong University

31 PUBLICATIONS 234 CITATIONS

SEE PROFILE

\section{Chen-Tung Arthur Chen}

National Sun Yat-sen University

340 PUBLICATIONS 8,770 CITATIONS

SEE PROFILE
READS
Xuelu Gao

Chinese Academy of Sciences

52 PUBLICATIONS 1,238 CITATIONS

SEE PROFILE

Fengxia Zhou

Chinese Academy of Sciences

8 PUBLICATIONS 95 CITATIONS

SEE PROFILE

Some of the authors of this publication are also working on these related projects:

Project National key research and development program View project

Project Distribution and sea-to-air flux of methane in coastal waters View project

All content following this page was uploaded by Xuelu Gao on 07 September 2016.

The user has requested enhancement of the downloaded file. All in-text references underlined in blue are added to the original document and are linked to publications on ResearchGate, letting you access and read them immediately. 
Baseline

\title{
Geochemistry of phosphorus in sediment cores from Sishili Bay, China
}

\author{
Yong Zhang ${ }^{\mathrm{a}}$, Xuelu Gao ${ }^{\mathrm{a}, \mathrm{a}, \mathrm{d}, *}$, Changyou Wang ${ }^{\mathrm{b}}$, Chen-Tung Arthur Chen ${ }^{\mathrm{c}}$, Fengxia Zhou ${ }^{\mathrm{a}, \mathrm{d}}$, Yuwei Yang ${ }^{\mathrm{a}}$

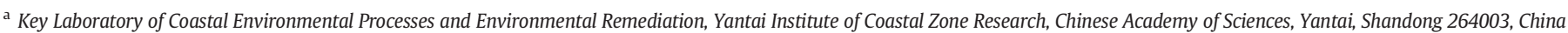 \\ b School of Marine Sciences, Nanjing University of Information Science and Technology, Nanjing, Jiangsu 210044, China \\ c Department of Oceanography, National Sun Yat-sen University, Kaohsiung 80424, Taiwan \\ ${ }^{\mathrm{d}}$ University of Chinese Academy of Sciences, Beijing 10049, China
}

\section{A R T I C L E I N F O}

Article history:

Received 20 June 2016

Received in revised form 17 August 2016

Accepted 22 August 2016

Available online $\mathrm{xxxx}$

\section{Keywords:}

Coastal waters

Sediment core

Phosphorus

Sequential extraction

Fractionation

\begin{abstract}
A B S T R A C T
This paper presents the distribution of total phosphorus $(\mathrm{P})$, inorganic $\mathrm{P}(\mathrm{IP})$ and organic $\mathrm{P}$ in sediment cores from Sishili Bay, China. Their concentrations ( $\mu \mathrm{mol} \mathrm{g}{ }^{-1}$ ) ranged from 15.04 to 21.59, 12.43 to 18.27 and 0.15 to 5.11 , respectively, showing $87.6-96.9 \%$ of TP is IP. The distribution of the fractionation of IP , obtained by a sequential extraction technique, was 1.9-3.2\% for soluble and loosely bound P (Ex-P), 8.5-13.1\% for Al-bound from (Al-P),

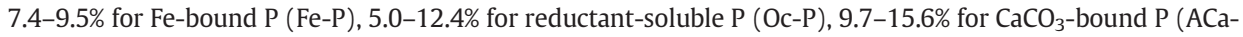
$\mathrm{P}$ ) and 45.9-54.6\% for detritus $\mathrm{P}$ (Det-P). The P distribution and concentration was consistent with other Chinese coastal seas. No significant difference was found for the sedimentary P forms between scallop cultivation area and background area, indicating that shellfish aquaculture did not have significant effect on the depositional environment in the studied area, at least in case of P.
\end{abstract}

(c) 2016 Elsevier Ltd. All rights reserved.
Phosphorus (P) is an essential macronutrient for all life. On geologic timescales, $\mathrm{P}$ is a limiting nutrient in oceanic biogeochemical cycles (Broecker, 1982; Smith, 1984; Tyrell, 1999). In recent decades, anthropogenic activities through the form of either gaseous, liquid or solid emissions have become the cause of many of environmental issues and are responsible for major global reorganizations of the biogeochemical cycles (Mackenzie et al., 2002). It was reported that by 2000, the total overall effect of land use activities on nutrients remobilization increased to 100 Mtons nitrogen $(\mathrm{N})$ and 50 Mtons $\mathrm{P}$ per year, with an average annual growth rate of the perturbation of $2 \%$ between 1950 and 2000 (Mackenzie et al., 2002). Besides, world fertilizer consumption puts another millions of tons of $\mathrm{N}$ and $\mathrm{P}$ each year to environment mainly in the forms of nitrate and phosphate (Mackenzie et al., 2002; Paytan and McLaughlin, 2007). Consequently, environment becomes enriched with biological available nutrients, and a significant part of which are transferred from land to coastal margin through soil erosion, mineral dissolution, surface water runoff and so on, making eutrophication become a common phenomenon in coastal water.

Because of its close relation with oceanic productivity and the marine biogeochemistry of many other key elements such as carbon and $\mathrm{N}$, marine $\mathrm{P}$ cycle has been the subject of intense study for more than three decades (e.g., Krom and Berner, 1981; Ruttenberg, 1992;

\footnotetext{
* Corresponding author at: Key Laboratory of Coastal Environmental Processes and Environmental Remediation, Yantai Institute of Coastal Zone Research, Chinese Academy of Sciences, Yantai, Shandong 264003, China.

E-mail address: xlgao@yic.ac.cn (X.Gao).
}

Filippelli, 1997; Van Den Broeck and Moutin, 2002; Moutin et al., 2008; Küster-Heins et al., 2010; Wang and Morrison, 2014). Paytan and McLaughlin (2007) estimated that almost 99\% of particulate and $25 \%$ of dissolved P from land are buried in coastal zone. So, understanding sedimentary $P$ in coastal zone is a vital link for the study of its global biogeochemical cycle.

The environmental behaviors of sedimentary elements depend strongly on their specific chemical forms or method of binding. A widely-used technique for understanding element distribution in the solid phase, which is known as fractionation, is based on the application of sequential selective chemical extractions. These methods are based on the rational use of a series of more or less selective reagents chosen to solubilize successively the different mineralogical fractions thought to be responsible for retaining the larger part of the trace elements (Wang et al., 2013a). They are intended to simulate the various possible natural and anthropogenic modifications of environmental conditions. The biogeochemistry of $\mathrm{P}$ in sediments is complicated. Inorganic $\mathrm{P}$ can react with calcium $(\mathrm{Ca})$, iron $(\mathrm{Fe})$ and aluminum $(\mathrm{Al})$ compounds to form discrete phosphates; organic $\mathrm{P}$ can be found in forms with varying resistance to microbial degradation. P can be transferred from water to sediment through biochemical and physical reactions, such as ion exchange, adsorption, and precipitation and also could be released from sediments as the overlying water quality changes. The behavior of sedimentary $\mathrm{P}$ is controlled by a number of biogeochemical processes such as microbial degradation of organic matter, desorption from iron (oxyhydr)oxides when iron reduction takes place and dissolution of P-containing mineral forms during geochemical alteration. 
Sishili Bay is a busy region in the south coast of the North Yellow Sea greatly affected by human activities mainly from urbanization. It is in the Shandong Peninsula Blue Economic Zone, the development of which is an important part of the national development strategy of China. Raft shellfish aquaculture, which has been banned since 2011, was once widespread in Sishili Bay for decades. The main objectives of this study are to assess the geochemistry of phosphorus in Sishili Bay sediment cores by determining its concentrations and chemical forms in which it occur using the sequential extraction procedure, and provide a background estimation of baseline data for future surveys on the responses of Sishili Bay environment to anthropogenic influences.

In this study, four sediment cores were collected in Sishili Bay and its adjacent area (Fig. 1). Cores B, C and D located in the scallop cultivation area, while core D situated in a clear sea area at the outside edge of the Sishili Bay. The sampling program was carried out in June 2009. The core samples were taken by a stainless steel gravity corer equipped with PVC internal tube liners. The cores from sites $B$ and $C$ were about $70 \mathrm{~cm}$ in length, the core from site $D$ was about $80 \mathrm{~cm}$ in length and the core from site E was about $100 \mathrm{~cm}$ in length. After collection, the cores were transported to laboratory within $3 \mathrm{~h}$. In laboratory, all cores were extruded and sliced into $2 \mathrm{~cm}$ intervals. The subsamples were homogenized and stored at $\sim{ }^{\circ} \mathrm{C}$ in the dark until further treatment.

We followed the sequential extraction procedure reported by Zhang and Kovar (2000) to determine different geochemical fractions of P. The six operational defined forms of $\mathrm{P}$ obtained through this scheme were: (1) exchangeable or loosely sorbed $\mathrm{P}(\mathrm{Ex}-\mathrm{P})$; (2) aluminum-bounded $\mathrm{P}$ (Al-P); (3) iron-bound P (Fe-P); (4) reductant-soluble P (Oc-P); (5) $\mathrm{CaCO}_{3}$-bound $\mathrm{P}$ (ACa-P); (6) detritus $\mathrm{P}$ (Det-P). The concentration of inorganic $\mathrm{P}$ (IP) was calculated as the sum of the six $\mathrm{P}$ forms mentioned above.

Freeze-dried samples were thoroughly ground, homogenized and sieved through a 200 mesh screen. Then $\sim 0.5 \mathrm{~g}$ of each sample was weighed and loaded to a $50 \mathrm{ml}$ centrifuge tube with $10 \mathrm{ml}$ solutions to perform the sequential extraction scheme. Ex-P was extracted with $1.0 \mathrm{M} \mathrm{MgCl}_{2}(\mathrm{pH}=7.0)$. Al-P was extracted with $0.5 \mathrm{M} \mathrm{NH}_{4} \mathrm{~F}(\mathrm{pH}=$ 8.0). Fe-P was extracted with $0.1 \mathrm{M} \mathrm{NaOH}-0.05 \mathrm{M} \mathrm{Na}_{2} \mathrm{CO}_{3}$. Oc-P was extracted with $\mathrm{CDB}(0.22 \mathrm{M}$ sodium citrate, $0.14 \mathrm{M}$ sodium dithionite, $1.0 \mathrm{M}$ sodium bicarbonate) $(\mathrm{pH}=7.6)$. ACa-P was extracted with 1.0 M NaAc-HAc ( $\mathrm{pH}=4)$. Det-P was extracted with $1.0 \mathrm{M} \mathrm{HCl}$. The content of total $\mathrm{P}$ was microwave digested. The concentration of $\mathrm{P}$ was determined by using an inductively coupled plasma optical emission spectrometer (Optima 7000 DV, PerkinElmer, USA). The organic P was calculated by subtracting inorganic $P$ from total $P$.
Between the extraction steps, solid/liquid separation was achieved by centrifuging at $4000 \mathrm{rpm}$ for $20 \mathrm{~min}$, the resulting supernatant being transferred to glass bottles and analyzed in time. Residues were then washed with $10 \mathrm{ml}$ de-ionized water, shaken for $15 \mathrm{~min}$, and centrifuged for $20 \mathrm{~min}$ at $4000 \mathrm{rpm}$, the supernatant also being analyzed. The sequential extraction procedure was carried out with no interruption once started. All plastic and glassware were pre-cleaned by soaking in $10 \% \mathrm{HNO}_{3}(\mathrm{v} / \mathrm{v})$ for at least 2 days, followed by soaking and rinsing with de-ionized water. All chemicals used in the experiment were guarantee-reagent grade. The analytical data quality was guaranteed through the implementation of laboratory quality assurance and quality control methods, including the use of standard operating procedures, analysis of reagent blanks, and analysis of replicates. All analyses of samples were carried out in triplicates and the RSDs were $<3 \%$.

The sample granulometry was analyzed using a Malvern Mastersizer 2000 laser diffractometer capable of analyzing particle sizes between 0.02 and $2000 \mu \mathrm{m}$. The percentages of the following 3 groups of grain sizes were determined: $<4 \mu \mathrm{m}$ (clay), 4-63 $\mu \mathrm{m}$ (silt), and $>63 \mu \mathrm{m}$ (sand). Total organic carbon (TOC) contents of the sample were determined using an Elementar vario MACRO cube CHNS analyzer after removing the inorganic carbon with $1 \mathrm{M} \mathrm{HCl}$.

Grain size composition and TOC content were measured to get the general characteristic of sediment samples used in this study.

As shown in Fig. 2, the studied sediment cores were dominated by high silt and sand contents. For core B, the clay contents increased gradually from $2.1 \%$ at surface to $6.6 \%$ at $70 \mathrm{~cm}$ depth with a mean of $4.0 \%$; for cores $\mathrm{C}$ and $\mathrm{D}$, the clay contents were generally within the range of 5$10 \%$, its average content in these two cores had very similar values of $8.5 \%$ and $8.3 \%$, respectively; for core E, the clay contents were within the range of $12-20 \%$ at most depths with a mean of $15.3 \%$. On average, except for core B, which was dominated by sand component, the other three cores were dominated by silt component. Like that of clay component, the silt content in core B increased downward from $25.6 \%$ to $70 \%$ at $70 \mathrm{~cm}$ depth with a mean of $44.5 \%$; the average silt contents in cores C, D and E were 58.6\%, 66.5\% and 63.0\%, respectively. The average contents of sand component in cores B, C, D and E were 51.5\%, 32.9\%, $24.9 \%$ and $21.8 \%$, respectively. The data of median grain size (D50) in the upper $20 \mathrm{~cm}$ depth of cores C, D and E exhibited a generally increasing trend downward, while they decreased from $\sim 105 \mu \mathrm{m}$ at surface to $\sim 60 \mu \mathrm{m}$ at $\sim 20 \mathrm{~cm}$ depth for core B; the D50 data showed no clear vertically variation trends below $20 \mathrm{~cm}$ depth for all the four cores (Fig. 3). According to the classification of Shepard (1954), the upper $15 \mathrm{~cm}$ sediment of core B was silty sand and the rest part of the core was mainly

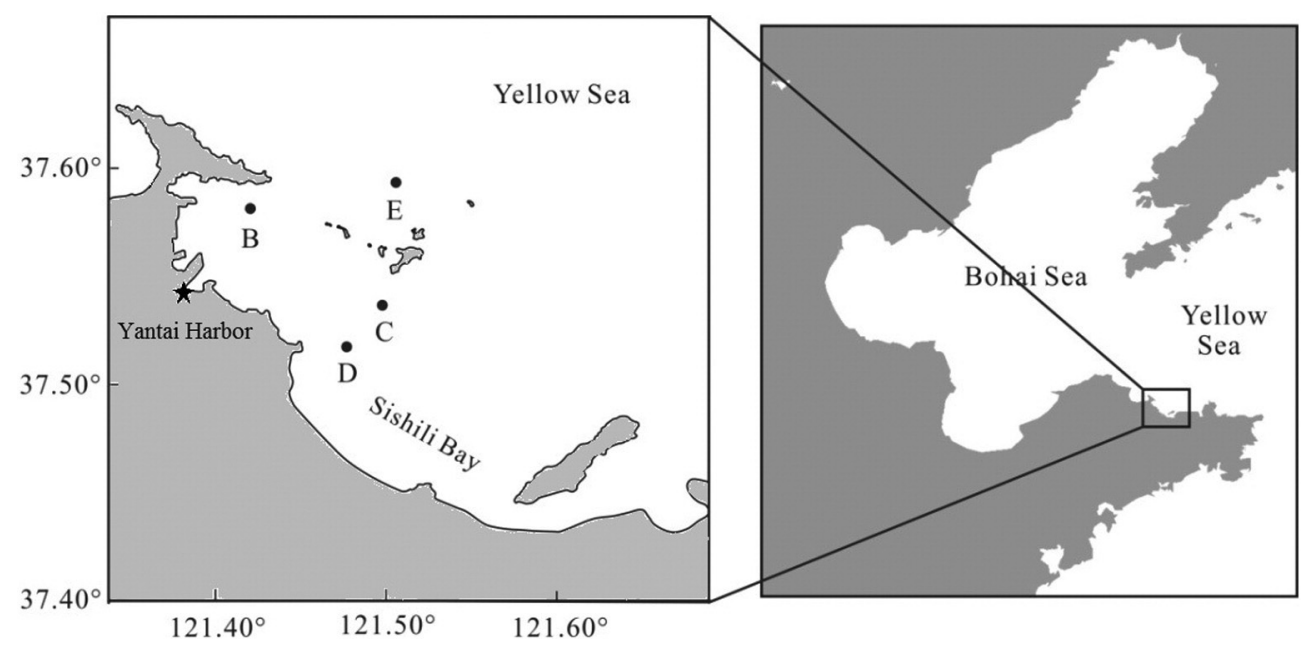

Fig. 1. Location of sampling sites (filled circles) in Sishili Bay. Filled star shows the place of Yantai Harbor. 
Baseline
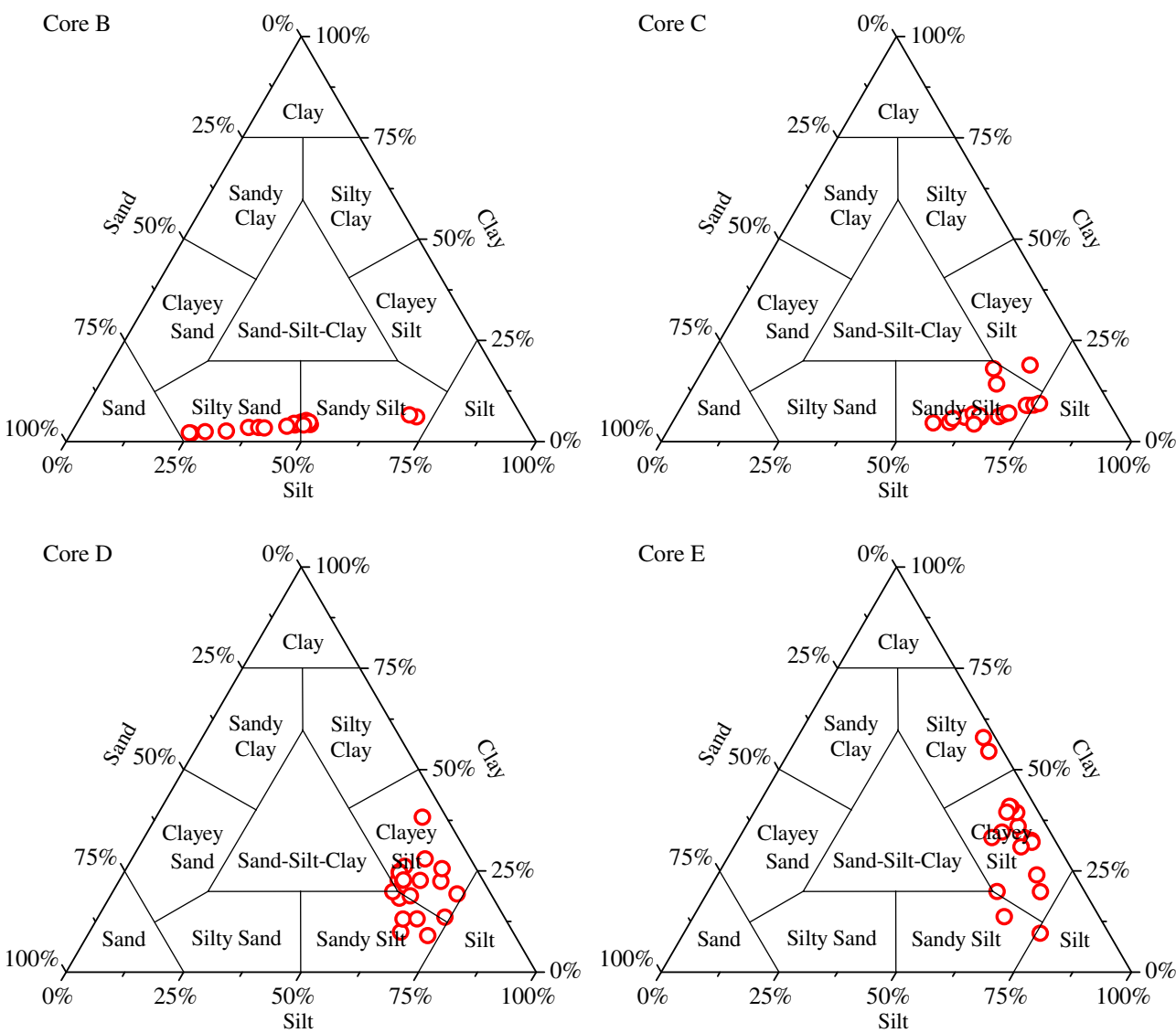

Fig. 2. Grain size compositions of the cores.

sandy silt; the sediments of cores C and D were almost clayey silt and sandy silt, respectively; the sediments of cores E were mainly clayey silt with some sandy silt layers (Fig. 2).

Reverse to that of D50, the TOC contents in cores C, D and E were highest at top layers and took on a decreasing trend downward in the upper $20 \mathrm{~cm}$ depth; below this depth, the TOC contents varied mainly within the relatively narrow range of $0.2-0.4 \%$ (Fig. 3). In core B, TOC

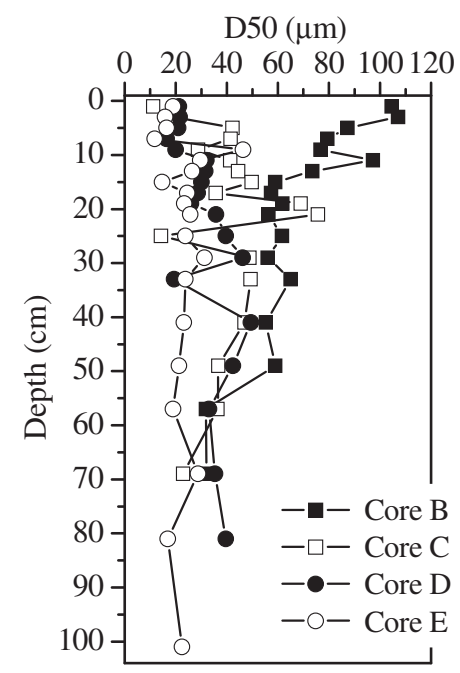

TOC $(\%)$
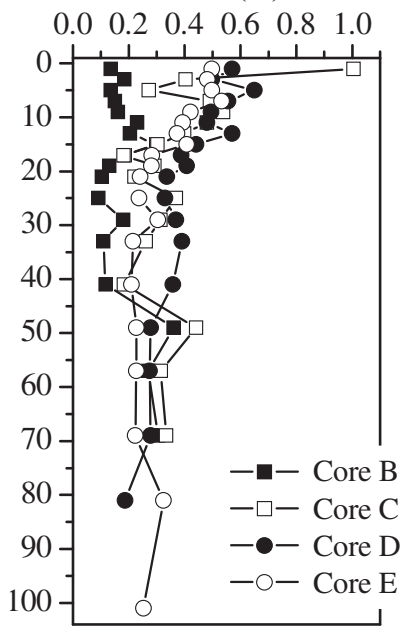

Fig. 3. Median grain size (D50) and TOC of the cores.

contents in the upper $40 \mathrm{~cm}$ were apparently lower than that of the other three cores and varied with the range of $0.1-0.2 \%$ with an exceptional high value of $0.3 \%$ at $15 \mathrm{~cm}$ depth, which was similar to the TOC contents below this depth (Fig. 3).

The water contents for cores B, C, D and E show little vertical variation and the average values are $25.3 \%, 31.1 \%, 31.1 \%$, and $33.3 \%$, respectively.

TP slightly varied between 15.85 and $16.50 \mu \mathrm{mol} \mathrm{g}^{-1}$ with a mean of $16.24 \mu \mathrm{mol} \mathrm{g}^{-1}$ in core B, increased from $16.10 \mu \mathrm{mol} \mathrm{g}^{-1}$ at top to $19.26 \mu \mathrm{mol} \mathrm{g}^{-1}$ at $10 \mathrm{~cm}$ and then decreased monotonously to $15.04 \mu \mathrm{mol} \mathrm{g}^{-1}$ at bottom in core C, ranged from 12.66 to $21.59 \mu \mathrm{mol} \mathrm{g}^{-1}$ (mean: $17.14 \mu \mathrm{mol} \mathrm{g}{ }^{-1}$ ) with a maximum value at $8 \mathrm{~cm}$ depth in core $\mathrm{D}$, and from 16.09 to $18.56 \mu \mathrm{mol} \mathrm{g}^{-1}$ (mean: $17.42 \mu \mathrm{mol} \mathrm{g}^{-1}$ ) with a maximum value at $10 \mathrm{~cm}$ depth in core $\mathrm{E}$

Table 1

Concentration of F1-F6, TOC and TP in cores B, C, D and E $\left(\mu \mathrm{mol} \mathrm{g}^{-1}\right)$.

\begin{tabular}{llllllllll}
\hline & & F1 & F2 & F3 & F4 & F5 & F6 & TOP & TP \\
\hline Core B & Min. & 0.21 & 1.29 & 0.97 & 1.13 & 1.12 & 7.21 & 0.22 & 15.85 \\
& Max. & 0.27 & 1.60 & 1.68 & 2.03 & 1.68 & 9.99 & 3.10 & 16.50 \\
& Mean & 0.25 & 1.38 & 1.21 & 1.58 & 1.47 & 8.86 & 1.50 & 16.24 \\
Core C & Min. & 0.22 & 1.57 & 1.30 & 1.51 & 1.39 & 6.68 & 0.15 & 15.04 \\
& Max. & 0.52 & 2.79 & 1.77 & 2.75 & 1.97 & 10.07 & 0.99 & 19.26 \\
& Mean & 0.32 & 2.22 & 1.47 & 2.12 & 1.65 & 8.71 & 0.52 & 17.01 \\
Core D & Min. & 0.41 & 1.42 & 0.76 & 0.59 & 1.83 & 6.74 & 0.23 & 12.66 \\
& Max. & 0.61 & 2.48 & 2.50 & 1.16 & 2.81 & 9.07 & 5.11 & 21.59 \\
& Mean & 0.47 & 1.82 & 1.63 & 0.86 & 2.29 & 7.95 & 2.13 & 17.14 \\
Core E & Min. & 0.47 & 1.29 & 0.90 & 0.91 & 2.34 & 6.27 & 0.52 & 16.09 \\
& Max. & 0.67 & 2.39 & 1.93 & 1.26 & 3.10 & 9.23 & 3.63 & 18.56 \\
& Mean & 0.55 & 1.70 & 1.37 & 1.08 & 2.72 & 7.99 & 2.01 & 17.42 \\
\hline
\end{tabular}



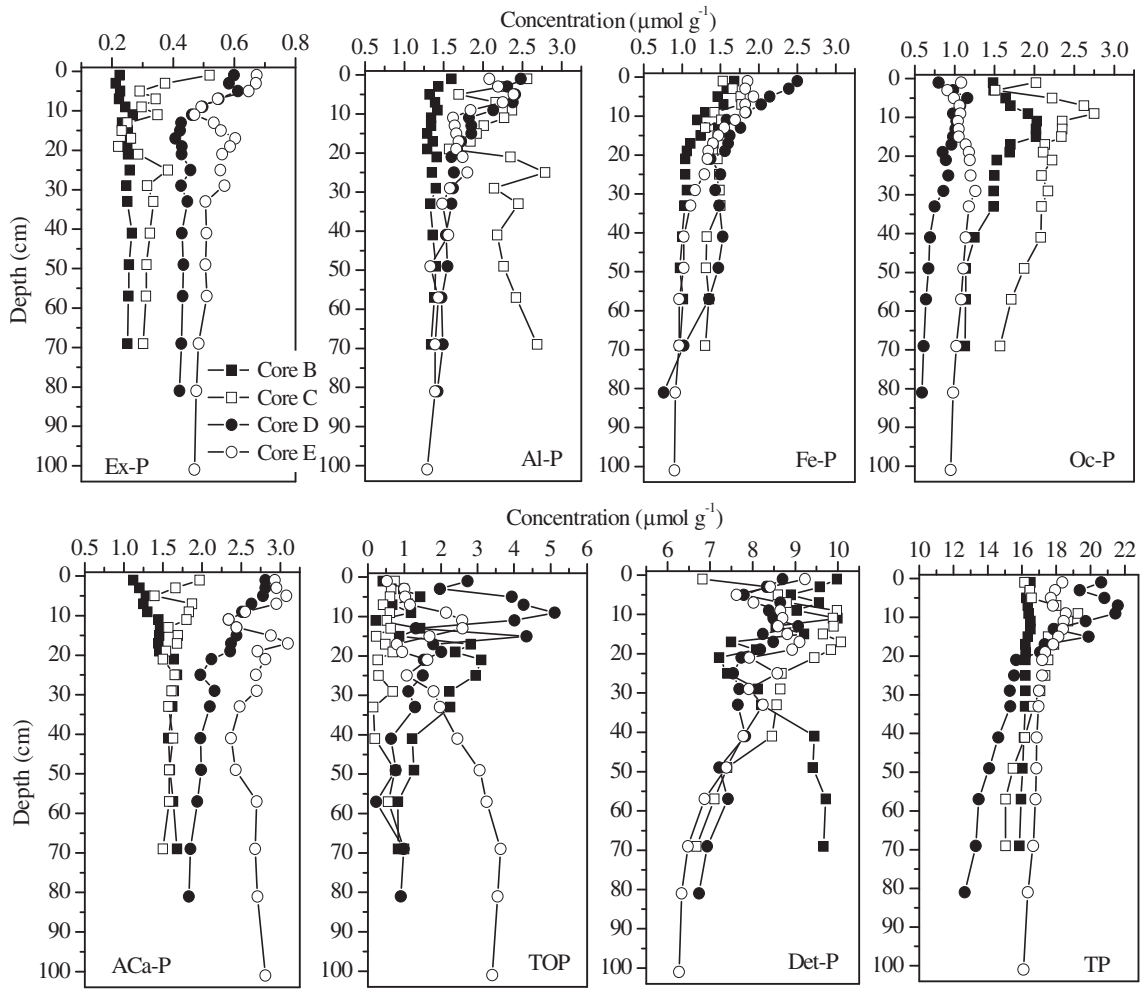

Fig. 4. Vertical distributions of F1-F6, TOP and TP.

Table 2

Comparison of concentrations of TP and TOP in different Chinese coastal areas $\left(\mu \mathrm{mol} \mathrm{g}{ }^{-1}\right)$.

\begin{tabular}{llll}
\hline Area & TP & TOP & References \\
\hline Core B in Sishili Bay & $15.85-16.50$ & $0.22-3.10$ & This study \\
Core C in Sishili Bay & $15.04-19.26$ & $0.23-0.99$ & This study \\
Core D in Sishili Bay & $12.66-21.59$ & $0.23-5.11$ & This study \\
Core E in Sishili Bay & $16.09-18.56$ & $0.52-3.63$ & This study \\
Jiaozhou Bay & $6.4-10.1$ & $0.32-5.00$ & Dai et al. (2006) \\
Bohai Sea & $10.8-20.3$ & $1.00-6.77$ & Jiang and Liu (2013) \\
Southwest Yellow Sea & $8.97-24.8$ & $0.11-8.61$ & Hong et al. (2010) \\
Yellow Sea & $14.4-18.3$ & $2.45-2.65$ & Cao and Liu (2010) \\
East China Sea shelf & $10.5-26.1$ & $1.28-4.66$ & Zhou et al. (2016) \\
East Sea & $13.4-22.5$ & $1.35-4.80$ & Zheng et al. (2003) \\
East Sea & $13.7-19.9$ & $2.11-3.81$ & Cao and Liu (2010) \\
Changjiang Estuary & $9.7-21.8$ & $0.76-5.68$ & Yang et al. (2015) \\
Changjiang Estuary & $15.0-21.4$ & $2.56-7.84$ & Meng et al. (2014) \\
Changjiang Estuary & $14.3-21.7$ & $\leq 0.37$ & Yu et al. (2013) \\
Pearl River Estuary & $11.0-18.7$ & $2.81-7.80$ & Yue et al. (2007) \\
\hline
\end{tabular}

(Table 1, Fig. 4). These results were comparable with those reported for the Jiaozhou Bay, the Bohai Sea, the Yellow Sea, the East China Sea, the Changjiang Estuary, and the Pear River Estuary (Table 2).

Ex-P followed the order of core B $\left(0.25 \pm 0.04 \mu \mathrm{mol} \mathrm{g}^{-1}\right)<$ core $\mathrm{C}$ $\left(0.32 \pm 0.06 \mu \mathrm{mol} \mathrm{g}^{-1}\right)<$ core $\mathrm{D}\left(0.47 \pm 0.06 \mu \mathrm{mol} \mathrm{g}{ }^{-1}\right)<$ core $\mathrm{E}$ $\left(0.55 \pm 0.06 \mu \mathrm{mol} \mathrm{g}{ }^{-1}\right)$. It varied at upper $30 \mathrm{~cm}$ and then kept almost constant below for cores C, D and E, while varied relatively little from top to bottom for core $\mathrm{B}$.

Al-P in cores B, D and E decreased downward and then merged at a value about $1.50 \mu \mathrm{mol} \mathrm{g}{ }^{-1}$. In core C, Al-P varied in a zig-zag form between 1.57 and $2.79 \mu \mathrm{mol} \mathrm{g} \mathrm{g}^{-1}$ at the top $40 \mathrm{~cm}$ and then increased downward slightly from 2.25 to $2.70 \mu \mathrm{mol} \mathrm{g}^{-1}$.

Fe-P decreased rapidly from top to $20 \mathrm{~cm}$ depth in all four cores, and then slightly below $20 \mathrm{~cm}$, making vertical distribution of Fe-P in cored $\mathrm{D}$ more like a right-leaned slim " $\mathrm{S}$ " than the other three ones do. The

Fractionation composition of TP

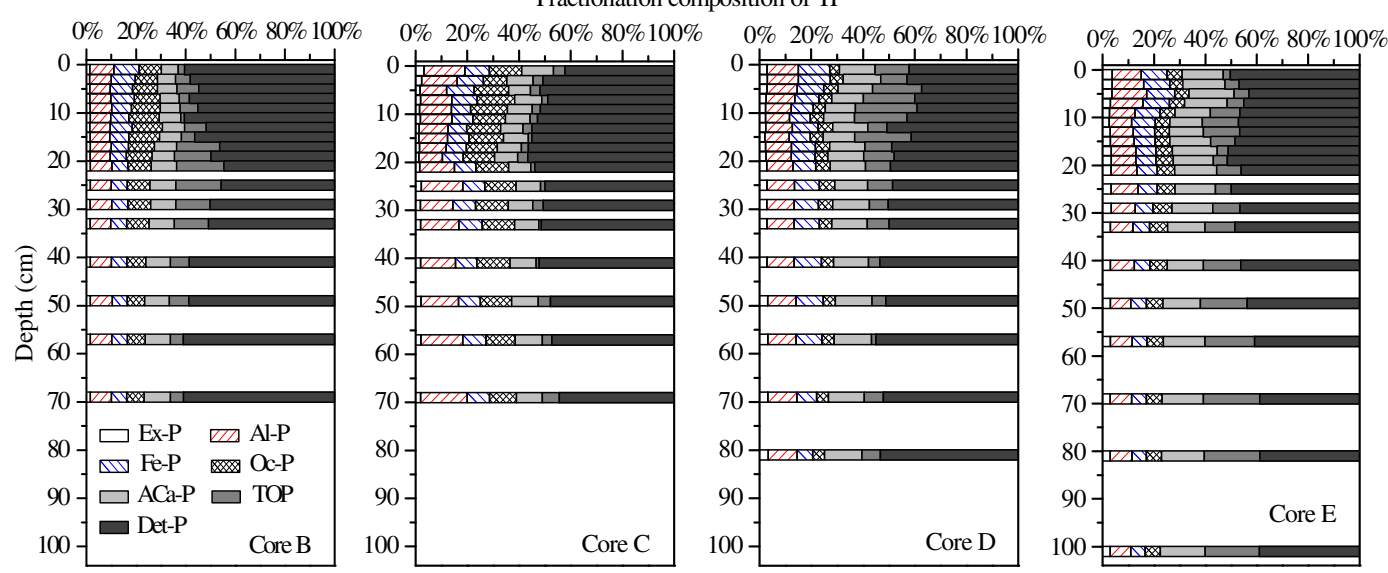

Fig. 5. Fractionation composition of TP in each studied core. 
Core B

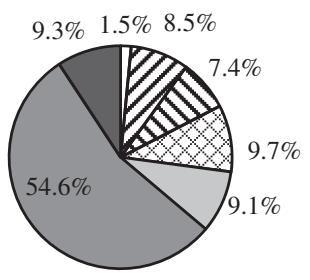

Ex-P WIIA Al-P
Core $\mathrm{C}$

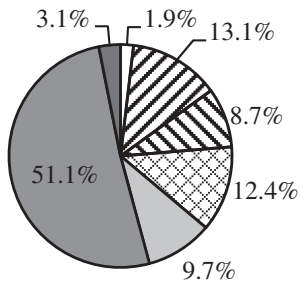

Core D

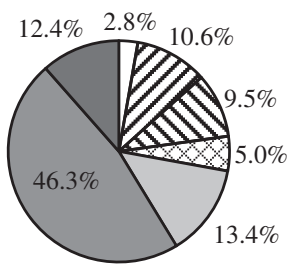

Core E

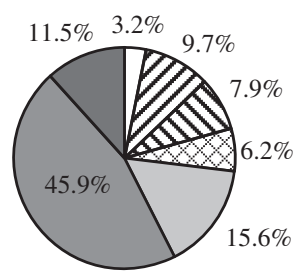

Fe-P

Oc-P

Fig. 6. Phase partitioning of different sedimentary phosphorus species in the Sishili Bay, including F1-F6 and TOP, based on average data.

mean values for cores B, C, D and E were $1.21 \mu \mathrm{mol} \mathrm{g}-1,1.47 \mu \mathrm{mol} \mathrm{g}^{-1}$, $1.63 \mu \mathrm{mol} \mathrm{g}^{-1}$ and $1.37 \mu \mathrm{mol} \mathrm{g}^{-1}$, respectively.

Oc-P peaked at $12.5 \mathrm{~cm}$ blow surface with a value of $2.03 \mu \mathrm{mol} \mathrm{g}{ }^{-1}$ in core $\mathrm{B}$, at $9 \mathrm{~cm}$ with a value of $2.75 \mu \mathrm{mol} \mathrm{g}{ }^{-1}$ in core $C$, at $5 \mathrm{~cm}$ with a value of $1.16 \mu \mathrm{mol} \mathrm{g} \mathrm{g}^{-1}$ in core $\mathrm{D}$, and $30 \mathrm{~cm}$ with a value of $1.26 \mu \mathrm{mol} \mathrm{g}^{-1}$ in core $\mathrm{E}$. The average values followed the same order as that of peak values do, i.e. $\mathrm{C}\left(2.12 \mu \mathrm{mol} \mathrm{g}^{-1}\right)>\mathrm{B}\left(1.58 \mu \mathrm{mol} \mathrm{g}{ }^{-1}\right)>\mathrm{E}$ $\mathrm{E}\left(1.08 \mu \mathrm{mol} \mathrm{g}^{-1}\right)>\mathrm{D}\left(0.86 \mu \mathrm{mol} \mathrm{g}^{-1}\right)$.

ACa-P generally increased downward from $1.12 \mu \mathrm{mol} \mathrm{g}^{-1}$ at top to $1.68 \mu \mathrm{mol} \mathrm{g}^{-1}$ at bottom in core $\mathrm{B}$, while decreasing from $2.81 \mu \mathrm{mol} \mathrm{g}{ }^{-1}$ at top to $1.83 \mu \mathrm{mol} \mathrm{g}^{-1}$ at bottom in core D. In core C, ACa-P varied between 1.39 and $1.97 \mu \mathrm{mol} \mathrm{g}^{-1}$ at top $12 \mathrm{~cm}$ and then kept almost constant downward at $1.65 \mu \mathrm{mol} \mathrm{g}^{-1}$. In core E, ACa-P varied between 2.34 and $3.10 \mu \mathrm{mol} \mathrm{g}{ }^{-1}$, more vigorously in the top $20 \mathrm{~cm}$ than below.
Det-P had a minimum value of $9.99 \mu \mathrm{mol} \mathrm{g}^{-1}$ at $21 \mathrm{~cm}$ depth in core $\mathrm{B}$, while maxima of $10.07 \mu \mathrm{mol} \mathrm{g}{ }^{-1}, 9.07 \mu \mathrm{mol} \mathrm{g}^{-1}$ and $9.23 \mu \mathrm{mol} \mathrm{g}^{-1}$ for C, D and E, respectively. Det-P was the most abundant fraction in sedimentary P of the study area. This result was in line with the findings in Changjiang estuary, Jiaozhou Bay, and East China Sea.

Summarizing the contents of Ex-P, Al-P, Fe-P, Oc-P, ACa-P, and Det-P mentioned above, we get the content of IP, i.e. $13.55-16.15 \mu \mathrm{mol} \mathrm{g}^{-1}$ in core $B, 13.33-18.34 \mu \mathrm{mol} \mathrm{g}^{-1}$ in core $C, 13.70-18.05 \mu \mathrm{mol} \mathrm{g}^{-1}$ in core $\mathrm{D}$, and $12.65-17.71 \mu \mathrm{mol} \mathrm{g}^{-1}$ in core E. These IP contents correspond to $74 \%-91 \%$ of TP in core B, $56 \%-92 \%$ of TP in core C, $65 \%-92 \%$ of TP in core $\mathrm{D}$, and $62 \%-88 \%$ of TP in core E. These results indicate that IP was the major constitute of TP, leaving OP the minor one.

TOP had a peak value of $3.10 \mu \mathrm{mol} \mathrm{g}-1$ at $22 \mathrm{~cm}$ in core B, varied slightly between 0.15 and $0.99 \mu \mathrm{mol} \mathrm{g}^{-1}$ in core $C$, varied between 0.23 and $5.11 \mu \mathrm{mol} \mathrm{g}^{-1}$ with peak value at $10 \mathrm{~cm}$ depth in core $\mathrm{D}$, and

Table 3

Correlation coefficients among various fractions of phosphorus.

\begin{tabular}{|c|c|c|c|c|c|c|c|c|c|}
\hline Core & & Ex-P & Al-P & Fe-P & Oc-P & ACa-P & Det-P & TIP & TOP \\
\hline \multirow[t]{9}{*}{ B } & Ex-P & & & & & & & & \\
\hline & Al-P & & & & & & & & \\
\hline & Fe-P & $-0.83^{* *}$ & $0.469^{*}$ & & & & & & \\
\hline & Oc-P & & & & & & & & \\
\hline & ACa-P & $0.704^{* *}$ & & $-0.91^{* *}$ & & & & & \\
\hline & Det-P & & & & & & & & \\
\hline & TIP & & & $0.585^{* *}$ & & $0.586^{*}$ & $0.937^{* *}$ & & \\
\hline & TOP & & & & & $-0.474^{*}$ & $-0.979^{* *}$ & $-0.982^{* *}$ & \\
\hline & $\mathrm{TP}$ & & & $0.782^{* *}$ & $0.776^{* *}$ & $0.733^{* *}$ & & & \\
\hline \multirow[t]{9}{*}{ C } & Ex-P & & & & & & & & \\
\hline & Al-P & $0.636^{* *}$ & & & & & & & \\
\hline & Fe-P & & & & & & & & \\
\hline & Oc-P & & & & & & & & \\
\hline & ACa-P & $0.578^{*}$ & & & & & & & \\
\hline & Det-P & $-0.548^{*}$ & $-0.552^{*}$ & & $0.688^{* *}$ & & & & \\
\hline & TIP & & & & $0.844^{* *}$ & & $0.901^{* *}$ & & \\
\hline & TOP & & & & & & & & \\
\hline & $\mathrm{TP}$ & & & & $0.839^{* *}$ & & $0.889^{* *}$ & $0.985^{* *}$ & \\
\hline \multirow[t]{9}{*}{$\mathrm{D}$} & Ex-P & & & & & & & & \\
\hline & Al-P & $0.916^{* *}$ & & & & & & & \\
\hline & Fe-P & $0.837^{* *}$ & $0.915^{* *}$ & & & & & & \\
\hline & Oc-P & $0.484^{*}$ & $0.690^{* *}$ & $0.633^{* *}$ & & & & & \\
\hline & ACa-P & $0.790^{* *}$ & $0.944^{* *}$ & $0.920^{* *}$ & $0.768^{* *}$ & & & & \\
\hline & Det-P & & $0.648^{* *}$ & $0.728^{* *}$ & $0.715^{* *}$ & $0.776^{* *}$ & & & \\
\hline & TIP & $0.738^{* *}$ & $0.920^{* *}$ & $0.939^{* *}$ & $0.795^{* *}$ & $0.968^{* *}$ & $0.881^{* *}$ & & \\
\hline & TOP & $0.507^{*}$ & $0.708^{* *}$ & $0.517^{*}$ & $0.739^{* *}$ & $0.690^{* *}$ & $0.549^{*}$ & $0.675^{* *}$ & \\
\hline & $\mathrm{TP}$ & $0.691^{* *}$ & $0.899^{* *}$ & $0.815^{* *}$ & $0.840^{* *}$ & $0.919^{* *}$ & $0.797^{* *}$ & $0.930^{* * *}$ & $0.899^{* *}$ \\
\hline \multirow[t]{9}{*}{$\mathrm{E}$} & Ex-P & & & & & & & & \\
\hline & Al-P & $0.755^{* *}$ & & & & & & & \\
\hline & Fe-P & $0.608^{* *}$ & $0.886^{* *}$ & & & & & & \\
\hline & Oc-P & & & & & & & & \\
\hline & ACa-P & $0.685^{* *}$ & $0.574^{* *}$ & & & & & & \\
\hline & Det-P & $0.525^{*}$ & $0.478^{*}$ & $0.666^{* *}$ & & & & & \\
\hline & TIP & $0.747^{* *}$ & $0.797^{* *}$ & $0.872^{* *}$ & & & $0.901^{* *}$ & & \\
\hline & TOP & $-0.841^{* *}$ & $-0.773^{* *}$ & $-0.690^{*}$ & & $-0.560^{*}$ & $-0.784^{* *}$ & $-0.917^{* *}$ & \\
\hline & $\mathrm{TP}$ & & $0.614^{* *}$ & $0.883^{* *}$ & & & $0.817^{* *}$ & $0.841^{* *}$ & $-0.556^{*}$ \\
\hline
\end{tabular}

Note: Only the values with $P<0.05$ were shown.

* $0.01<P<0.05$ (two-tail test).

** $P<0.01$ (two-tail test). 
increased from $0.52 \mu \mathrm{mol} \mathrm{g}{ }^{-1}$ at top to $3.63 \mu \mathrm{mol} \mathrm{g}^{-1}$ at near bottom in core E. The contents of OP in Sishili Bay were consistent with those in the other Chinese coastal areas (Table 2). Compared to IP, TOP was a minor constitute of TP.

The fractionation composition of TP in every core showed little vertical variation (Fig. 5). The exchangeable fraction was always the least (1.5\%-3.2\%) and the Det-P always the highest (46.3-54.6\%, Fig. 5).

The column-averaged values followed the order of Ex-P $(1.5 \%)<\mathrm{Fe}-$ $\mathrm{P}(7.4 \%)<\mathrm{Al}-\mathrm{P}(8.5 \%)<\mathrm{ACa}-\mathrm{P}(9.1 \%)<\mathrm{TOP}(9.3 \%)<$ Oc-P $(9.7 \%)<$ Det-P (54.6\%) in core B, Ex-P (1.9\%) < TOP $(3.1 \%)<$ Fe-P $(8.7 \%)<$ ACa-P $(9.7 \%)<$ Oc-P $(12.4 \%)<\mathrm{Al}-\mathrm{P}(13.1 \%)<$ Det-P $(51.1 \%)$ in core C, Ex-P $(2.8 \%)<$ Oc-P $(5.0 \%)<$ Fe-P $(9.5 \%)<$ Al-P $(10.6 \%)<$ TOP $(11.5 \%)<$ ACa$\mathrm{P}(13.4 \%)<\operatorname{Det}-\mathrm{P}(46.3 \%)$ in core D, and Ex-P (3.2\%) < Fe-P $(7.4 \%)<$ Al-P $(8.5 \%)<$ ACa-P $(9.1 \%)<$ TOP $(9.3 \%)<$ Oc-P $(9.7 \%)<$ Det-P (54.6\%) in core $\mathrm{E}$ (Fig. 6).

Among different forms of sedimentary P, Ex-P, Al-P, Fe-P and TOP may be readily released to ambient water through desorption, reductive dissolution and degradation, making them bioavailable. The mean values of potential bioavailable P in cores B, C, D and E is 6.09, 7.90, $8.78,9.34 \mu \mathrm{mol} \mathrm{g}^{-1}$, respectively, corresponding to $26.7 \%, 26.8 \%, 35.3 \%$ and $32.3 \%$ of TP. The bioavailable P in this study is much higher than those in the Changjiang Estuary (3.60-5.35 $\mu \mathrm{mol} \mathrm{g}{ }^{-1}$, Meng et al., 2014; Yang et al., 2015) and East China Sea shelf (3.50-4.10 $\mu \mathrm{mol} \mathrm{g}^{-1}$, Zhou et al., 2016).

Pearson correlation matrix is presented in Table 3. For core D, the positive relationship among all the P species means that they have common external sources, probably from terrestrial industrial effluents and domestic sewage inputs since it is the closest site to the coastal populated residence. For core E, positive relationship was found among IP species, while TOP was negative related to the other species, indicating that the IP species mainly come from the mineralization of TOP. Compared to cores $\mathrm{D}$ and $\mathrm{E}$, cores $\mathrm{B}$ and $\mathrm{C}$ present weak correlation among different $\mathrm{P}$ species. The negative relationships between Ex-P and Fe-P, Fe-P and $\mathrm{ACa}-\mathrm{P}$ in core B and between Ex-P and Det-P, Al-P and Det-P in core C indicate that they can transform between each other, while the positive relationships indicate that they may have common sources.

De-P is usually found to be concentrated in sand fraction, while other P fractions concentrated in clay and silt fractions (Yu et al., 2011, 2013; Meng et al., 2014, 2015; Zhuang et al., 2014; Zhou et al., 2016). In core D, all $\mathrm{P}$ species are positively related to water content, TOC and silt and negatively related to sand (Table 4), which confirms that all P species have common external sources delivered by silt, instead of sand. Furthermore, the bury rate may exceed the mineralization rate of OP to IP. In core E, All IP species and TP exhibit positive relationship with water content and TOC, and negative relationship with silt. TOP negatively related to water content and TOC, but positively related to silt. These results show that TOP was mainly buried in silt and mineralized to IP which was favored under high water content. The produced IP species was not contained in silt again. Besides the mineralization produced IP, there are some minor external input of IP along with TOC.

TP values in the cores of Sishili Bay varied from $12.66 \mu \mathrm{mol} \mathrm{g}^{-1}$ to $21.59 \mu \mathrm{mol} \mathrm{g}^{-1}$, falling within the range defined by those in Chinese coastal seas. Furthermore, no significant difference was found among the sedimentary P forms between Scallop cultivation area (core B, core $\mathrm{C}$, and core $\mathrm{D}$ ) and background area (core E). These results indicate that shellisish aquaculture did not have significant effect on the depositional environment, at least in case of P. Given a sedimentation rate of $0.78-0.91 \mathrm{~cm} /$ year (Wang et al., 2013a, 2013b), the increase of TP in the upper $20 \mathrm{~cm}$ (Fig. 4) is coincident with a time span from mid1980 s to the sampling date. During this period, the quickly-developed human activities around Sishili Bay including fertilizer use, marine dumping and sewage discharge have contributed to the eutrophication (Wang et al., 2013a, 2013b), which includes enrichment of TP.

Bioavailable $\mathrm{P}$ has higher concentration, while TOP has relative lower concentration and is similar to those in other Chinese coastal areas. This finding was consistent to the previous result reported
Table 4

Correlation coefficients between various fractions of phosphorus and the main geochemical parameters of sediments.

\begin{tabular}{|c|c|c|c|c|c|c|}
\hline Core & Fraction of $\mathrm{P}$ & Water content & TOC & Clay & Silt & Sand \\
\hline \multirow[t]{9}{*}{ B } & Ex-P & & & & & \\
\hline & Al-P & & & & & \\
\hline & Fe-P & & & $-0.757^{* *}$ & $-0.763^{* *}$ & $0.765^{* *}$ \\
\hline & Oc-P & $-0.820^{* *}$ & & $-0.482^{*}$ & $-0.536^{*}$ & $0.533^{*}$ \\
\hline & ACa-P & & & $0.778^{* *}$ & $0.778^{* *}$ & $-0.78^{* *}$ \\
\hline & Det-P & & & & & \\
\hline & TIP & & & & & \\
\hline & TOP & & & & & \\
\hline & $\mathrm{TP}$ & $-0.707^{* *}$ & -0.430 & $-0.849^{* *}$ & $-0.890^{* *}$ & $0.889^{* * *}$ \\
\hline \multirow[t]{9}{*}{ C } & Ex-P & $0.548^{*}$ & $0.748^{* *}$ & $0.482^{*}$ & $0.654^{* *}$ & $-0.666^{* *}$ \\
\hline & Al-P & & & $0.709^{* *}$ & & $-0.561^{*}$ \\
\hline & Fe-P & & & & & \\
\hline & Oc-P & & & & & \\
\hline & ACa-P & $0.551^{*}$ & $0.743^{* *}$ & 0.095 & $0.621^{* *}$ & $-0.485^{*}$ \\
\hline & Det-P & & & $-0.656^{* *}$ & & \\
\hline & TIP & & & $-0.516^{*}$ & & \\
\hline & TOP & & & & & \\
\hline & $\mathrm{TP}$ & & & $-0.488^{*}$ & & \\
\hline \multirow[t]{9}{*}{ D } & Ex-P & $0.820^{* *}$ & $0.731^{* *}$ & & $0.654^{* *}$ & $-0.678^{* *}$ \\
\hline & Al-P & $0.867^{* *}$ & $0.885^{* *}$ & & $0.802^{* *}$ & $-0.807^{* *}$ \\
\hline & Fe-P & $0.809^{* *}$ & $0.860^{* *}$ & & $0.643^{* *}$ & $-0.664^{* *}$ \\
\hline & Oc-P & $0.682^{* *}$ & $0.817^{* *}$ & & $0.646^{* *}$ & $-0.616^{* *}$ \\
\hline & ACa-P & $0.799^{* *}$ & $0.915^{* *}$ & & $0.818^{* *}$ & $-0.808^{* *}$ \\
\hline & Det-P & $0.553^{*}$ & $0.804^{* *}$ & & $0.575^{* *}$ & $-0.589^{* *}$ \\
\hline & TIP & $0.803^{* *}$ & $0.938^{* *}$ & & $0.753^{* *}$ & $-0.760^{* *}$ \\
\hline & TOP & $0.553^{*}$ & $0.690^{*}$ & & $0.736^{* *}$ & $-0.730^{* *}$ \\
\hline & $\mathrm{TP}$ & $0.753^{* *}$ & $0.901^{* *}$ & & $0.813^{* *}$ & $-0.815^{* *}$ \\
\hline \multirow[t]{9}{*}{ E } & Ex-P & $0.782^{* *}$ & $0.535^{*}$ & & & \\
\hline & Al-P & $0.625^{* *}$ & $0.820^{* *}$ & & $-0.490^{*}$ & \\
\hline & Fe-P & $0.689^{* *}$ & $0.885^{* *}$ & & $-0.580^{* *}$ & \\
\hline & Oc-P & $0.529^{*}$ & $0.475^{*}$ & & & \\
\hline & ACa-P & $0.512^{*}$ & $0.453^{*}$ & & & \\
\hline & Det-P & $0.705^{* *}$ & $0.488^{*}$ & & $-0.660^{* *}$ & $0.528^{*}$ \\
\hline & TIP & $0.813^{* *}$ & $0.661^{* *}$ & & $-0.624^{* *}$ & \\
\hline & TOP & $-0.765^{* *}$ & $-0.492^{*}$ & & $0.514^{*}$ & \\
\hline & $\mathrm{TP}$ & $0.657^{* *}$ & $0.711^{* *}$ & & $-0.607^{* *}$ & $0.483^{*}$ \\
\hline
\end{tabular}

Note: Only the values with $P<0.05$ were shown.

* $0.01<P<0.05$ (two-tail test).

** $P<0.01$ (two-tail test).

by Li et al. (2013) and demonstrated that IP is the primary factor affecting the trophic state of seawater in Sishili Bay. The bioavailable P may come from the industrial wastewater and domestic sewage from surrounding land. In addition, surface runoff caused by heavy rainfall in June (wet season) may contain large quantities of bioavailable $P$ when it flows through surrounding land and finally pours into the Sishili Bay. The high concentration of bioavailable P may play an important role in the summer peak of chlorophyll $a$ observed by Shen et al. (2014).

The molar ratios of TOC to TOP (TOC/TOP) of marine phytoplankton are close to the Redfield ratio 106 (Redfield et al., 1963), while the ratios of TOC/TOP of terrestrial plants have much higher values (Wang et al., 2010; Sardans et al., 2012). So it can be used to assess the influence of terrestrial organic matter inputs, i.e. TOC/TOP higher than 106 are usually attributed to the dominance of terrestrial sources. In this study, the ratio of TOC/TOP was 23-214 with a mean of 60 in core B, 32-217 with a mean of 98 in core C, 45-118 with a mean of 79, and 26-172 with a mean of 57 in core E (Fig. 7). For core E, ratios of TOC/TOP are higher than the Redfield ratio in the top $2 \mathrm{~cm}$, then decrease sharply to around 35 and keep constant below. This profile indicates that the terrestrial inputs influence only the surface sediment therein and that the abundance of P relative to carton during organic matter deposition keeps a long history record. For the other cores, ratios of TOC/TOP varied irregularly from top to bottom, probably due to the frequent disturbance caused by annual channels dredge for the Yantai harbor or bottom trawling. 
TOC/TOP

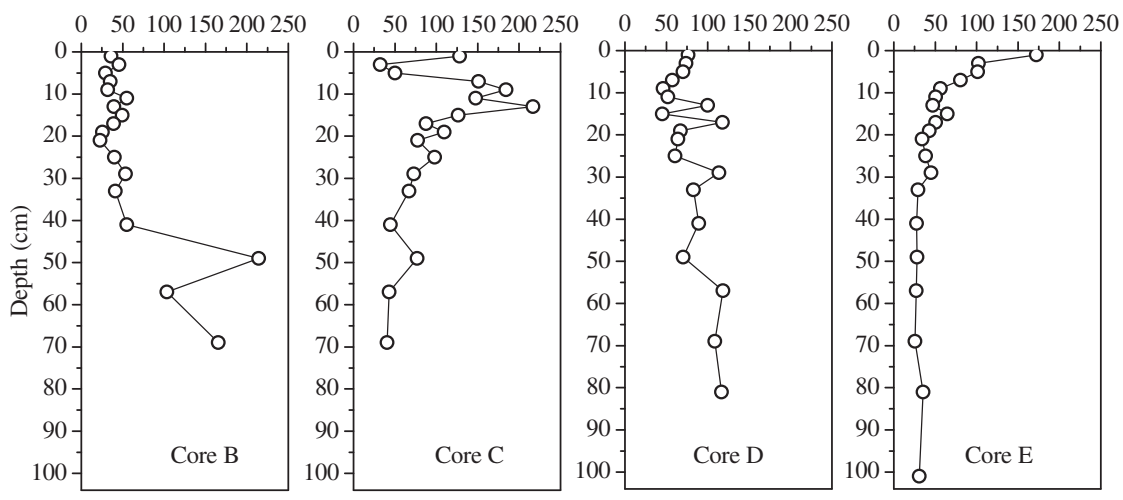

Fig. 7. Ratio of TOC/TOP in the studied cores.

\section{Acknowledgements}

This study was financially supported by the Strategic Priority Research Program of the Chinese Academy of Sciences, Grant Nos. XDA11020702, XDA11020305 and XDA11020102.

\section{References}

Broecker, W.S., 1982. Ocean chemistry during glacial time. Geochim. Cosmochim. Acta 46, 1689-1705.

Cao, W.Q. Liu, S.M., 2010. A study on inorganic and organic phosphorus in core sediment of the Yellow and East China Seas. Periodical of Ocean University of China 40 (1), 069-074 (in Chinese).

Dai, J.C., Song, J.M., Li, X.G., Zheng, G.X., Yuan, H.M., 2006. Phosphorus and its environmental marker function in Jiaozhou Bay sediment. Environ. Sci. 27 (10), 1953-1962 (in Chinese).

Filippelli, G.M., 1997. Controls on phosphorus concentration and accumulation in oceanic sediments. Mar. Geol. 139, 231-240.

Hong, Y.N., Geng, J.J., Qiao, S., Zhang, Y.Z., Ding, L.L., Wang, X.R., Ren, H., 2010. Phosphorus fractions and matrix-bound phosphine in coastal surface sediments of the Southwest Yellow Sea. J. Hazard. Mater. 181, 556-564.

liang, H.H., Liu, S.M., 2013. Distribution and burial flux of phosphorus in sediments of the Bohai Sea. Acta Sci. Circumst. 33 (1), 125-132 (in Chinese).

Krom, M.D., Berner, R.A., 1981. The diagenesis of phosphorus in a nearshore marine sediment. Geochim. Cosmochim. Acta 45, 207-216.

Küster-Heins, K., Steinmetz, E., De Lange, G.J., Zabel, M., 2010. Phosphorus cycling in marine sediments from the continental margin off Namibia. Mar. Geol. 274 (1-4), 95-106.

Li, B., Bai, Y.Y., Xin, H.Y., Ma, Y.Q., Song, X.K., Zhang, X.Z., Sun, Y.Z., Liu, Y.H., Qin, H.W. 2013. Trophic state of seawater and ecological characteristics of phytoplankton in Sishili Bay. Acta Ecol. Sin. 33 (1), 0260-0266.

Mackenzie, F.T., Ver, L.M., Lerman, A., 2002. Century-scale nitrogen and phosphorus controls of the carbon cycle. Chem. Geol. 190, 13-32.

Meng, J., Yao, P., Yu, Z.G., Bianchi, T.S., Zhao, B., Pan, H.H., Li, D., 2014. Speciation, bioavailability and preservation of phosphorus in surface sediments of the Changiiang Estuary and adjacent East China Sea inner shelf. Estuar. Coast. Shelf Sci. 144, 27-38.

Meng, I., Yao, P., Bianchi, T.S., Li, D., Zhao, B., Xu, B.C., Yu, Z.G., 2015. Detrital phosphorus as a proxy of flooding events in the Changjiang River Basin. Sci. Total Environ. 517, 22-30.

Moutin, T., Karl, D.M., Duhamel, S., Rimmelin, P., Raimbault, P., Van Mooy, B.A.S., Claustre, H., 2008. Phosphate availability and the ultimate control of new nitrogen input by nitrogen fixation in the tropical Pacific Ocean. Biogeosciences 5, 95-109.

Paytan, A., McLaughlin, K., 2007. The oceanic phosphorus cycle. Chem. Rev. 107, 563-576.

Redfield, A.C., Ketchum, B.H., Richards, F.A., 1963. The influence of organisms on the composition of seawater. In: Hill, M.N. (Ed.)The sea vol II. Wiley, London, pp. 26-77.

Ruttenberg, K.C., 1992. Development of a sequential extraction method for different forms of phosphorus in marine sediments. Limnol. Oceanogr. 37, 1460-1482.

Sardans, J., Rivas-Ubach, A., Peñuelas, J., 2012. The elemental stoichiometry of aquatic and terrestrial ecosystems and its relationships with organismic lifestyle and ecosystem structure and function: a review and perspectives. Biogeochemistry 111, 1-39.
Shen, C.Y., Shi, P., Zhao, H., 2014. Spatial-temporal distribution characteristics of chlorophyll $a$ and the controlling factors in the Sishili Bay of Yantai. Marine Sciences 38 (9), 33-38.

Shepard, F.P., 1954. Nomenclature based on sand-silt-clay ratios. J. Sediment. Petrol. 24, $151-158$

Smith, S.W., 1984. Phosphorus versus nitrogen limitation in the marine environment. Limnol. Oceanogr. 29, 1149-1160.

Tyrell, T., 1999. The relative influence of nitrogen to phosphorus on oceanic primary production. Nature 400, 525-531.

Van Den Broeck, N., Moutin, T., 2002. Phosphate in the sediments of the Gulf of Lions (NW Mediterranean Sea), relationship with input by the river Rhone. Hydrobiologia 472, 85-94.

Wang, C., Morrison, R.J., 2014. Phosphorus speciation and changes with depth in the sediment of Lake Illawarra, New South Wales, Australia. Environ. Earth Sci. 71 (8), 3529-3541

Wang, Y.P., Law, R.M., Pak, B., 2010. A global model of carbon, nitrogen and phosphorus cycles for the terrestrial biosphere. Biogeosciences 7, 2261-2282.

Wang, C.Y., Zhang, Y., Li, H.L., Morrison, R.J., 2013a. Sequential extraction procedures for the determination of phosphorus forms in sediment. Limnology 14, 147-157.

Wang, Y.J., Liu, D.Y., Richard, P., Li, X., 2013b. A geochemical record of environmental changes in sediments from Sishili Bay, northern Yellow Sea, China: anthropogenic influence on organic matter sources and composition over the last 100 years. Mar. Pollut. Bull. 22, 227-236.

Yang, B., Cao, L., Liu, S.M., Zhang, G.S., 2015. Biogeochemistry of bulk organic matter and biogenic elements in surface sediments of the Yangtze River Estuary and adjacent sea. Mar. Pollut. Bull. 96, 471-484.

Yu, Y., Song, J.M., Li, X.G., Yuan, H.M., Li, N., Duan, L.Q., 2011. Distributions and environmental implications of the phosphorus forms in the surface sediments from the Changiiang Estuary. Advances in Earth Science 26 (8), 870-880 (in Chinese).

Yu, Y., Song, J.M., Li, X.G., Yuan, H.M., Li, N., Duan, L.Q., 2013. Environmental significance of biogenic elements in surface sediments of the Changjiang Estuary and its adjacent areas. J. Environ. Sci. 25 (11), 2185-2195.

Yue, W.Z., Huang, X.P., Sun, C.C., 2007. Distribution and pollution of nitrogen and phosphorus in surface sediments from the Pearl River estuary. Oceanologia et Limnologia Sinica 38 (2), 111-117 (in Chinese).

Zhang, H., Kovar, J., 2000. Phosphorus fractionation. In: Pierzynski, G.M. (Ed.), Methods of Phosphorus Analysis for Soils, Sediments, Residuals and Waters. North Carolina State University, pp. 50-59.

Zheng, L.B., Ye, Y., Zhou, H.Y., Wang, H.Z., 2003. Distribution of different forms of phosphorus in seabed sediments from East China Sea and its environmental significance. Oceanologia et Limnologia Sinica 34 (3), 274-282 (in Chinese).

Zhou, F.X., Gao, X.L., Yuan, H.M., Song, J.M., Chen, C.T.A., Lui, H.K., Zhang, Y., 2016. Geochemical forms and seasonal variations of phosphorus in surface sediments of the East China Sea shelf. J. Mar. Syst. 159, 41-54.

Zhuang. W., Gao, X.L., Zhang, Y., Xing, Q.G., Tosi, L., Qin, S., 2014. Geochemical characteristics of phosphorus in surface sediments of two major Chinese mariculture areas: the Laizhou Bay and the coastal waters of the Zhangzi Island. Mar. Pollut. Bull. 83 (1), 343-351. 